REVISTA CRIOULA N ${ }^{\circ} 19-1^{\circ}$ SEMESTRE $/ 2017$

\title{
La Malinche em Xicoténcatl (1826) e na históRia: O IMAGINÁRIO COLETIVO MEXICANO EM CONFIGURAÇÕES CONFRONTADAS
}

\author{
Leila Shaí Del Pozo González ${ }^{1}$ \\ Gilmei Francisco Fleck ${ }^{2}$
}

DOI 10.11606/issn.1981-7169.crioula.2017.125505

RESUMO: O artigo analisa a configuração literária de Malinche no primeiro romance histórico latino-americano, o anônimo Xicoténcatl (1826). Objetivamos mostrar a criticidade neste romance oitocentista e ao mesmo tempo comparar as imagens de Malinche na obra com os estudos históricos sobre essa personagem, apontando distanciamentos e aproximações entre o exposto em Xicoténcatl e o que se registra na história sobre Malinche.

ABSTRACT: The article discusses the literary configuration of Malinche in the first Latin American Historical Novel, the anonymous Xicoténcatl (1826). The aim is to present the critical nature of this 19th century novel and at the same time to compare Malinche's images in it with the historical studies about this character pointing out to approaches and gaps between what is exposed in Xicoténcatl and what is registered in History about Malinche.

PALAVRAS-CHAVE: La Malinche; Xicoténcatl (1826); romance histórico latino-americano.

KEYWORDS: La Malinche; Xicoténcatl (1826); Latin American Historical Novel.

1 Mestranda em Letras pela Universidade Estadual do Oeste do Paraná (UNIOESTE). E-mail: eilashai@hotmail.com

2 Doutor em Literatura Comparada e Tradução pela Universidade de Vigo e pela Universidade Estadual Paulista - UNESP/ Assis. E-mail: chicofleck@yahoo.com.br 
2 romance histórico Xicoténcatl (1826) é a primeira produção híbrida de história e ficção da América Latina. Esta obra é pouco conhecida no Brasil devido ao fato de que ainda não se publicou a sua única tradução em português, feita por Gilmei Francisco Fleck (2013), com a colaboração de Anthoni Cley Sobierai. Este romance anônimo foi publicado em espanhol na Filadélfia, Estados Unidos. Xicoténcatl (1826) é considerado por Fleck (2014) o embrião do novo romance histórico latino-americano, cuja eclosão se deu em 1949, com a publicação de El reino de este mundo, do cubano Alejo Carpentier. Tal consideração feita pelo pesquisador advém do fato dessa obra ser um claro exemplo de como o pensamento latino-americano se posicionou criticamente frente às imposições do cânone europeu - evidenciadas na modalidade clássica de romance histórico scottiana - já no Romantismo e, por meio do romance histórico Xicoténcatl, deu início ao processo de questionamento da sua formação histórica, já a inícios do século XIX, fato que é a essência da escrita do novo romance histórico latino-americano, mais de um século depois.

Este romance nasce crítico, pois, na sua criação, o autor utiliza a crônica escrita por Antonio de Solís - Historia verdadeira de la conquista de la Nueva España (1632), registro historiográfico que defende ideologicamente o discurso da Restauração Espanhola, na qual o herói máximo é Hernán Cortés - e, ao citar vários trechos dela, consegue reinterpretar o discurso da história oficial, levantando novas perspectivas na leitura da história da "conquista" da América espanhola e traz à tona a crítica ao status quo do poder colonial espanhol. 
A narrativa romanesca trata da saga de Xicoténcatl, o jovem - um líder da etnia tlaxcalteca -, o autóctone que se opõe historicamente a Hernán Cortés. Na diegese, o protagonista é configurado dentro dos padrões dos heróis clássicos e é mostrado como o representante autóctone dos povos latino-americanos no contexto da chegada de Cortés ao continente. Além disto, quem é colocado na posição do vilão na diegese é o herói da crônica de Solís, o próprio Hernán Cortés, ao se evidenciar, no romance, o seu lado mais vil. Dessa forma, em Xicoténcatl rompe-se o cânone europeu ao configurar os excluídos como protagonistas e ao expor como vilão um herói da história oficial.

O autor anônimo utiliza-se da história oficial como único fio narrativo - diferente do modelo scottiano, que apresenta dois fios narrativos: um ficcional, com os protagonistas imaginados e outro, como pano de fundo, seguindo a história oficial, com personagens de extração histórica ficcionalizados em papeis secundários. Entre as personagens de Xicoténcatl está La Malinche - ou doña Marina, nome utilizado no romance - que está representada, em papel secundário, como uma entre os colaboradores autóctones de Cortés.

Apesar de o romance ter "autor anônimo", sabe-se dele ter sido um ideólogo republicano. Este propõe, na obra, a tese do México ser, como representação da América Latina, uma nação predestinada, aos modos do pensamento oitocentista do destino manifesto estadunidense (FORERO QUINTERO, 2012). Para isso, apresenta, claramente, dois grupos antagônicos: os heróis, todos autóctones - liderados por Xicoténcatl, o jovem, e sua amada 
Teutila, única personagem que não é de extração histórica - e Xicoténcatl, o velho, pai do herói - exemplo de determinação, coragem e dignidade. No grupo dos antagonistas de Hernán Cortés, encontram-se Diego de Ordaz única personagem espanhola, configurada como impoluta e exemplar -, o frei Bartolomé de Olmedo - que adota o discurso colonizador pregado pela religião católica - que, na prática, não passa de mais um dos soldados de Cortés, além dos aliados autóctones Magiscatzin e doña Marina, que, conforme a tese do romance procura mostrar, foram corrompidos pelo contato com os brancos europeus.

O biógrafo de Malinche, Ricardo Herren (1993), afirma que as bases para a formação do mito de La Malinche foram tomadas desta obra. Portanto, neste artigo apontamos algumas dessas imagens da personagem de extração histórica e as cotejamos com os estudos de Ricardo Herren (1993), Francis Karttunen (1997) e Sandra Messinger Cypess (2000), com o intuito de verificar se estas imagens do imaginário coletivo mexicano são aquelas apresentadas no romance Xicoténcatl (1826) em relação a esta destacada autóctone.

Atualmente - em consequência do movimento nacionalista mexicano de inícios do século $\mathrm{XX}$ - o imaginário coletivo mexicano considera a personagem histórica Malinche como a responsável pela queda do Império Asteca e pela facilitação da conquista para os espanhóis, liderados por Cortés, devido a seu papel de intérprete.

A Malinche mitificada carrega um lado positivo e outro negativo, pois ela passa a ser considerada como "la Eva-Malinche en palabras de Sonia Montecino, y [...] la 'madre y puta, 
traidora y útero simbólico de la nación mexicana' en la conocida frase de Fernanda Núñez Becerra." (MARTIN, 2007,

p. 11). Esse seria, ainda, o modo como o povo mexicano e alguns estudiosos vêm considerando a personagem histórica. No entanto, se compararmos essas imagens da nativa com os registros históricos, anteriores ao período nacionalista mexicano que buscou revalorizar o autóctone, veremos que não se considerava a figura dessa personagem histórica de maneira tão negativa. (KARTTUNEN, 1997).

A primeira imagem de Malinche no romance Xicoténcatl (1826) é evocada pela personagem Ordaz. Este a menciona numa conversa com frei Bartolomé e a aponta como: "quizá víctima de su seducción [de Cortés]." (ANÓNIMO, [1826] 1964, p. 85). A configuração de personagem impoluta, que Ordaz faz de Malinche, permite lançar dúvidas sobre o que teria levado "essa mulher autóctone a tal situação" e, nesse contexto, expressa que talvez ela seja vítima da sedução de Cortés. Esta menção deve ser levada em consideração com relação ao pacto de leitura entre o leitor e o narrador, pois, ao colocar essa opinião na voz da única personagem europeia configurada como pessoa íntegra, parece-nos bastante significativa nesse sentido. Desse modo, abre-se a possibilidade de interpretar a conduta de Malinche como sendo resultado de ela ter sido vítima da sedução de Cortés. Não rejeitamos, no entanto, a probabilidade de que essa voz da personagem Ordaz seja também a camuflagem da voz do narrador, no trecho.

Assim, o fragmento mostra o ponto inicial para a configuração circular concedida pelo autor a esta personagem de extração histórica - La Malinche - no texto romanesco de 1826: 
"uma autóctone, bom selvagem, vítima da sedução de Cortés”. Por outro lado, essa construção se distancia da situação de escravidão da Malinche histórica. Os escravos não escoIhem nem precisam ser seduzidos pelo amo, simplesmente acatam ordens.

Logo, ao avançar na leitura da diegese de Xicoténcatl, a configuração da doña Marina expõe outras faces. No seguinte trecho, encontramos a primeira caracterização de Malinche feita pela voz narrativa:

[...] después de varios accidentes de fortuna, vino a ser esclava del cacique de Tabasco. Este la pasó al dominio de Hernán Cortés, después de la sumisión de su país, con otras esclavas que le presentó de regalo. Los buenos talentos y las gracias de esta esclava llamaron la atención de su amo, el que, después de haberla hecho bautizar con el nombre de Marina, puso en ella su amor y su confianza, de manera que en pocos días pasó de su esclava a su concubina y confidenta. (ANÓNIMO, 1964, p. 99).

A pesquisadora Sandra Messinger Cypess (2000) afirma que neste recorte não se demonstra simpatia por Malinche, pois, pelas palavras utilizadas pelo autor anônimo - después de vários accidentes de fortuna, vino a ser esclava del cacique de Tabasco - ela poderia ter sido qualquer outra que chegasse também por meio de vários acidentes do destino até Cortés. Neste ponto, ficção e história não convergem. Como aponta Karttunen (1997), não houve outra como Malinche na história americana após Colombo. A habilidade de aprender línguas, 
o dom de mando, a disposição da personagem histórica, seus conhecimentos do mundo indígena e o momento histórico foram quesitos que deram lugar à participação única dessa personagem na história.

Mas, tudo isto tem uma razão fundamental: a tese do autor anônimo. Na obra pretende-se demonstrar que a 'Conquista de México pelos espanhóis' se deu graças à corrupção dos nativos que ajudaram nos planos de Cortés. Assim, todos os nativos são configurados como bons selvagens, segundo imagem de Rousseau, sem exceção. No final da narrativa, todos os malvados se redimem e Malinche, como nós veremos adiante, volta aos usos morais autóctones, reafirmando a tese da narrativa.

A seguinte imagem de Malinche, em Xicoténcatl, tem a ver com a primeira reação de Cortés ao conhecê-la: "Los buenos talentos y las gracias de esta esclava llamaron la atención de su amo, el que, después de haberla hecho bautizar con el nombre de Marina, puso en ella su amor y su confianza". Da cena, depreende-se o cuidado e o carinho que Cortés tem para com essa dádiva dos autóctones, a quem dá, imediatamente, seu amor e confiança e a torna sua concubina e confidente. Por outro lado, as mesmas palavras que descrevem a atitude de Cortés não fazem referência ao proceder da personagem doña Marina, sendo possível a leitura de certa frieza por parte dela. Nesse sentido, constrói-se a imagem de que Cortés tudo dá, Malinche somente recebe.

Townsend (apud WOOD, 2007, p. 220) afirma: "[...] the adolescent indigenous girl started her new life among the inva- 
ders as a slave 'who had no choice in the matter' except to do as she was told." Ao que tudo indica, a condição de escrava a que a personagem histórica esteve submetida não impediu o autor anônimo de criar uma situação romanesca em que a personagem Cortés fosse atraída pelos atributos da personagem Malinche e tivesse que seduzi-la.

Nos "anais da história", contudo, lemos que a personalidade histórica Cortés procurou sempre dividir o saque com seus homens, pois sabia que esse tipo de ação assegurava-Ihe a lealdade da hoste. Por saque, entenda-se, não somente joias, bens preciosos etc., mas também muIheres. Como confirma Herren (1993, p. 25), "las hembras cumplían la función de objetos de intercambio en el mundo masculino", não somente autóctone, mas também "hasta cierto punto, entre los españoles. Ambas culturas admitían la esclavitud como institución legítima [...]." (HERREN, 1993, p. 25). Por outro lado, Herren (1993, p. 25-26) relata, sobre a personagem histórica, que:

Cortés repartió prontamente las mujeres entre sus oficiales. La de mejor aspecto de entre ellas, moza menuda de cuerpo y ojos despiertos, que tendría unos dieciséis años correspondió al capitán de más abolengo [...]: Alonso Hernández de Portocarrero, [...].

A Malinche histórica não caiu, imediatamente, nas mãos do conquistador Hernán Cortés, pois ele a deu ao seu favorito Alonso Hernández de Portocarrero. Passaram-se dias para que Cortés percebesse o potencial de Malinche como 'língua'. O biógrafo de Malinche comenta que, na falta de um intérprete 
de Nahuatl, em certa ocasião, Cortés a viu conversando na língua de uma comitiva autóctone a quem o intérprete espanhol Aguilar não conseguia entender, segundo as crônicas de Francisco López de Gómara: "Cortés Ilamó aparte a Marina, junto a Aguilar, y le prometió más que su libertad si ella conseguía la amistad de los mexicas con él, indicándole que la queria además como su intérprete y secretaria." (HERREN, 1993, p. 27).

Com respeito ao batismo de Malinche, mencionado nesta citação, Herren (1993, p. 26) esclarece este ponto afirmando que, historicamente, as escravas recebidas foram batizadas para cumprir a lei que proibia: "mantener acceso ni coito carnal con ninguna mujer, fuera de nuestra ley." Porém, segundo o estudioso, isso, na verdade, era uma interpretação curiosa do sexto mandamento da religião que não permite fornicar fora do matrimônio; os conquistadores entendiam que: "tal interdicción no existía siempre y cuando su compañera de cama no fuera 'pagana', sino Cristiana. [...]. Así, el bautismo las convertía en legítimas hembras de cama de los españoles permitiendo paradójicamente, los pecados de la carne." (HERREN, 1993, p. 26).

As informações históricas contribuem para a compreensão de como é caracterizada a personagem literária. Esta correlação implícita entre informação histórica e ficcional ocorre em todo o romance. Portanto, para entender este trecho, recorremos, novamente, a Herren (1993), que torna compreensível os aspectos históricos desse episódio. Segundo ele, durante a conquista espanhola das Américas não houve tempo nem espaço para o amor. A principal função das cativas não 
sacrificadas nos templos era encarregar-se dos afazeres do lar: fazer farinha para a tortilha de milho, o pão de cada dia dos mexicanos e, quando tinham a idade e atrativos suficientes, serviam na cama aos seus amos.

Ainda, segundo Herren (1993), as relações sexuais não eram consideradas pecado, pois se tratava de escravas. A moral 'asteca', segundo o estudioso, era similar à 'cristã', no sentido em que havia aspectos repressivos com respeito às mulheres: a virgindade e a fidelidade conjugal eram as principais virtudes femininas e o adultério era brutalmente punido. Todavia, isso não se aplicava às escravas, como era o caso de Malinche.

Mariano García Somonte afirma que:

No hay por qué creer que doña Marina fuera la amante del distinguido aristócrata [Hernández de Portocarrero], capitán a cuyos servicios entró como criada. Tampoco fue Marina la amante o querida de Cortés, como no lo fueron las demás hijas de caciques que repartió entre sus capitanes. (GARCÍA SOMONTE apud HERREN, 1993, p. 42).

As afirmações de García Somonte, acreditamos como Herren, não convertem as mulheres autóctones e os conquistadores em "seres assexuados". Contudo, prova que houve sexo, consentido ou não, sem, necessariamente, existir sentimentos ou laços entre as escravas e os seus amos. Concordamos com Herren quando afirma que as cativas não eram amásias ou concubinas, como interpreta Salvador de Madarriaga (apud HERREN, 1993), pois, na realidade, as relações entre nativas batizadas e espanhóis foram: "maratónicos contactos sexuales de los conquistadores con las 
nativas realizados dentro de inveteradas y poco cristianas prácticas poligínicas." (HERREN, 1993, p. 42-43).

Assim, sobre a afirmação no romance de que a personagem de extração histórica Cortés: "puso en ella su amor y su confianza, de manera que en pocos días pasó de su esclava a su concubina y confidenta", entendemos que tal situação romanesca apresenta pouca convergência com a história, como visto até este momento. A Malinche histórica passou ao leito de Cortés só após o fato de Alonso Hernández de Portocarrero ser designado como mensageiro, junto a Francisco de Montejo, para voltar à Espanha, em 26 de julho de 1519 (HERREN, 1993). Como afirma o biógrafo de Marina, "es probable [...] que Cortés quisiera matar dos pájaros de un tiro. Pero la principal preocupación del capitán [...] era conseguir la aquiescencia del monarca después de su rebelión [...] frente al gobernador Velázquez." (HERREN, 1993, p. 72).

Não houve amor. Este ponto é difícil de analisar, pois cada pesquisador poderia entrar no perigo de acrescentar praticamente qualquer coisa, tal qual afirma Townsend (apud WOOD, 2007). Malinche não deixou escrita a sua própria história e somente temos as escritas de outros sobre ela. Dessa forma, Townsend (apud WOOD, 2007) recomenda tentar capturar a perspectiva única de Malinche em eventos cruciais, rastreando seus passos por meio de todas as fontes que a mencionam ou ajudam a reconstituir o viés autóctone do período de maneira geral.

O biógrafo Herren (1993, p. 141) afirma que: "no parece [...] haya habido sitio para un ápice de romanticismo en las relaciones de Cortés con todas sus mujeres, sin exceptuar a 
Marina." Entretanto, o autor anônimo, contrariando uma possível aproximação com a história, utiliza a cena do Cortés amoroso do início da narrativa para, depois, condenar Malinche em três cenas da obra, atribuindo-lhe, dessa forma, a imagem de monstro sexual, como veremos na cena, em Xicoténcatl, a seguir:

[...] Difícil sería querer pintar la sorpresa del honrado español al oír la libre declaración de amor que le hizo doña Marina. Esta le dijo que, [...] su afecto no había podido resistir al mérito y prendas de un hombre tan honrado como Ordaz; que, si ella fuera libre, no dudaría un momento en la elección y abandonaría al instante a su opresor, para darse toda entera a sus inclinaciones; pero que, no pudiendo en su condición de esclava obrar conforme a su libre voluntad, quería lo menos robar a su tirano los instantes que pudiese, vengándose así de su opresión [...]. (ANÓNIMO, 1964, p. 101).

O trecho inteiro citado inclui uma das imagens de Malinche: a de "monstro sexual", relacionada com os símbolos de traição (a Cortés) e de prostituição que o imaginário mexicano construiu dela. Isso ocorre devido a que, nessa passagem do romance, mostra-se o 'seu lado libidinoso' ao desejar ter Ordaz para si. De acordo com Karttunen (1997, p. 297), "[t] o this day it seems that hardly any writer, male or female, can describe her in any terms but sexual."

Todavia, a relação entre as personagens históricas Malinche e Ordaz foi criada pelo autor anônimo para mostrar não só a perfídia da 'língua de Cortés', mas, também, de 
acordo com Cypess (2000), como sinédoque para a interação das mulheres autóctones com os europeus que gerou mestiços. A personagem ficcional doña Marina, dessa forma, é ligada, diretamente, no romance, a La Chingada - termo utilizado por Octavio Paz (apud HERREN, 1993) para significar aquela mulher que se abre ao outro. Esta imagem de La Malinche segue em conformidade com a tese geral do autor anônimo que busca revelar os efeitos da invasão europeia no México, que foram prejudiciais e nefastos à vida política, cultural e sexual da América (CYPESS, 2000).

A seguir, expomos outro recorte do romance que mostra uma Malinche desleal:

Hernán Cortés había encargado a doña Marina que, con maña y dulzura procurase hacerla desconfiar de Xicoténcatl, prevaliéndose para ello de las conversaciones que tuviera con él [...]. Mas como las intrigas no siempre llenan su objeto, por esta vez obraron lo contrario de lo que se había propuesto Cortés. Doña Marina conocía bien cuánto podía perjudicar a sus intereses destruir el amor de Teutila, y así sólo aconsejaba a ésta que no se dejase seducir de las palabras dulces ni de las expresiones virtuosas de los españoles, que diestros en el engaño, no trataban más que burlarse de la necia credulidad de sus víctimas. (ANÓNIMO, 1964, p. 113).

No fragmento, permanece a ideia de uma Malinche que desobedece às ordens, quando necessário, e o faz sem hesitar, pois vela pelos próprios interesses. A imagem dela como alguém que ousa não obedecer às ordens de seu 
amo, fica, porém, pouco convergente com as crônicas que, tal como Herren (1993) afirma, mostram que a personagem histórica obedecia como o faz um bom soldado de caráter firme e íntegro.

A Malinche ficcional comunica para Teutila somente o conveniente e manipula-a para conseguir encaminhar os fatos a seu favor. Além disso, ela é infiel a Teutila - a jovem namorada de Xicoténcatl acredita ter em Malinche uma amiga sincera - ao se insinuar a Xicoténcatl. A narrativa, não obstante, deixa claro que doña Marina age dessa forma de maneira a não se comprometer diretamente, pois, simplesmente, procura por um subterfúgio caso seja necessário ter um lugar para onde fugir. Sendo assim, descobrimos a imagem de Malinche manipuladora.

Dessa forma, a configuração de doña Marina apresenta a imagem de 'mulher falsa', tanto frente a seus conterrâneos, quanto a Cortés. Nossa leitura, ao igual que Cypess (2000), percebe o modo como a personagem lida com os problemas e os soluciona, fazendo uso do que aprendeu "das más artes dos europeus". Esse aspecto está presente na maior parte do romance, mas, ao longo da narrativa isso muda.

No seguinte trecho do romance, escolhido entre os que retratam a personagem Malinche, podemos observar uma mudança significativa na apresentação da personagem. Ela está quase por ganhar seu filho, iniciam-se as dores de parto. Nesse momento de grande dor, doña Marina se confessa para o frei Bartolomé de Olmedo:

[...]-No, padre mío — decía a su confesor-; no hay remedio para mí. Yo soy una grande pecado- 
ra y es menester que todo el Universo conozca mis culpas y vea mis remordimientos, que el martirio que sufro sirva de ejemplo y de escarmiento a los que, como yo, abandonan la senda de la virtud. [...]. (ANÓNIMO. 1964, p. 139).

Nessa passagem, a narrativa mostra a Malinche assumindo as suas culpas: 'Yo soy una grande pecadora'. Logo, a personagem pretende que sua experiência de vida 'sirva de ejemplo y de escarmiento a los que, como yo, abandonan la senda de la virtud'. Servir de exemplo e andar pelo caminho da virtude são duas questões importantes que valem como instrumento didático para o narrador.

Finalmente, mostramos o momento em que fecha-se o círculo configurativo adjudicado à Malinche no romance: "Di a Hernán Cortés que su esclava amasará su pan, que lavará sus ropas, pero que no volverá a ser la cooperadora de sus planes ambiciosos ni su cómplice en sus desórdenes." (ANÓNIMO, 1964 , p. 153). Esse momento é uma declaração de renúncia da personagem nativa à moral europeia aprendida, pois ela desiste da sua posição de colaboradora ativa de Cortés, para continuar a ser, somente escrava. Ela já não deseja mais fazer parte dos "planos ambiciosos" e dos "desmandos" do seu amo. Obedecerá a ele, ainda que contra a sua vontade, para voltar ao caminho da virtude autóctone.

Depois de verificar as imagens da personagem histórica Malinche nesta obra, confirmamos, sim, a possibilidade de que estas imagens negativas em Xicoténcat podem ter sido tomadas como base para a construção do mito Eva-Malinche. Nada obstante, o imaginário coletivo 
mexicano abandona o aspecto humano da personagem ficcional na narrativa.

O nosso olhar, mais de acordo com a nossa contemporaneidade, vê nas linhas do romance a saga de uma mulher valente, a quem o narrador atribui uma configuração que permite mostrá-la com defeitos e virtudes, uma personagem ficcional tão verossímil como um ser humano real. Os novos paradigmas dos pensamentos teóricos de nossa era nos deixam mais permissivos, mais compreensivos.

Por outro lado, com respeito à verificação das imagens concedidas à Malinche no romance Xicoténcatl e os registros históricos sobre ela, acreditamos que a história e a narrativa nesta obra nem sempre convergem. Vários aspectos inseridos na configuração da personagem de extração histórica são convenientemente acrescentados para dar valor à tese, proposta pelo autor anônimo, do bom selvagem que, corrompido, como no caso da personagem Malinche, no final viesse a arrepender-se, abandonando todo o aprendido com os europeus para voltar aos seus costumes morais autóctones anteriores, pois, neles há virtude e esperança na formação de uma nova nação. 


\section{REFERÊNCIAS BIBLIOGRÁFICAS}

ANÓNIMO. Xicoténcatl. Prólogo, organização, estudo preliminar e notas de Antonio Castro Leal. [2. ed.]. pp. 73-177. In: CASTRO LEAL, Antonio (Org.). La novela del México colonial. México: Aguilar, 1964.

CYPESS, Sandra Messinger. La Malinche in Mexican Literature. 4 ed. Austin: University of Texas Press, 2000. Retrieved from: <https://books.google.com.br/books?id=AveyrqzQOGIC\&p$\mathrm{g}=\mathrm{PA} 41 \& \mathrm{hl}=\mathrm{pt}-\mathrm{BR} \&$ source=gbs_toc_r\&cad=3\#v=onepage\&q\&f=false>. Access in: 05 oct. 2016.

FLECK, Gilmei Francisco. O romance histórico - uma breve trajetória. In: ABRÃO, Daniel; GIACON, Eliane M. de O. (Orgs.). Pesquisa em literatura. Deslocamentos, conexões e diferenças. Reflexões de crítica, teoria e historiografia literárias do mestrado em letras da Universidade Estadual de Mato Grosso do Sul. Curitiba: Appris, 2014.

FORERO QUINTERO, Gustavo. Estudio preliminar y notas. In: ANÓNIMO. Xicotencatl. Madrid: Vervuert, 2012.

HERREN, Ricardo. Doña Marina, La Malinche. México: Ed. Planeta, 1993.

KARTTUNEN, Frances. Rethinking Malinche. In: SCHROEDER, Susan; WOOD, Stephanie; HASKETT, Robert (editors). Indian women of early Mexico. s.n.: University of Oklahoma Press, 
1997. pp. 291-314. Disponível em: <https://books.google.com. $\mathrm{br} / \mathrm{C} \& p g=\mathrm{PA} 291 \& \mathrm{lpg}=\mathrm{PA} 291 \& \mathrm{dq}=\% \mathrm{E} 2 \% 80 \% 9 \mathrm{CR}$ ethinking+Malinche. $\%$ E2\%80\%9D+Indian+Women+of+Early+Mexico.\&sour$\mathrm{ce}=$ bl\&ots $=4 \mathrm{NGal} 45 \mathrm{jEZ} \&$ sig=vSI6qf4Orlotviy1FgHCQLvofSl\&hl=pt-BR\&sa=X\&ved=0ahUKEwih6pnd0ZTPAhXCDZAKHZYjDZcQ6AEIlzAB\#v=onepage\&q=\%E2\%80\%9CRethinking\%20 Malinche.\%E2\%80\%9D\%20Indian\%20Women\%20of\%20Early$\% 20$ Mexico.\&f=false>. Acesso em 16 set. 2016.

MARTíN, Maria Teresa Díez. Perspectivas historiográficas: mujeres indias en la sociedad colonial hispanoamericana. Frentes Avanzados de la Historia. Revista de difusión histórica interatlántica y de género/S- Investigación, genealogía profesional. Universidad Nacional de Educación a Distancia. UNED/España. 2007. Disponível em: <http://maytediez.blogia.com/2007/022704-perspectivas-historiograficas-mujeres-indias-en-la-sociedad-colonial-hispanoamer.php >. Acesso em: 02 jan. 2015.

WOOD, Stephanie. Contextualizing Malinche. Review of Camilla Townsend's Malintzin's Choices: An Indian Woman in the Conquest of Mexico (Albuquerque: University of New Mexico Press, 2006). A Contracorriente, v. 4, n. 3, p. 219-233, 2007.

Submissão: 2017-02-09

Aceite: 2017-03-31 